\title{
Personal Strategy and Change Readiness
}

\author{
Jehiel Zif \\ Professor of Business Administration \\ Hult International Business School, Boston, Ma., USA \\ $\&$ \\ Tel-Aviv University, Faculty of Management, Tel-Aviv, Israel \\ E-mail: Jehiel.zif@faculty.hult.edu \\ Jziv1@post.tau.ac.il
}

Received: Nov. 1, 2015

Accepted: Dec. 18, 2015

Published: January 1, 2016

doi:10.5296/jmr.v8i1.8659

URL: http://dx.doi.org/10.5296/jmr.v8i1.8659

\begin{abstract}
Guidelines for developing personal strategy are based on strategic concepts for business and a framework of well-being. The notion is that effective strategy has to balance a deliberate and specific plan with an evolving strategy of change as a result of new opportunities and threats. The set of personal objectives to be prioritized are a modified version of flourishing components in positive psychology. Alternative life styles are presented based on the objectives. The building blocks of the strategy are borrowed from the Balanced Score Card methodology. The paper emphasizes the importance of personal strengths in choosing initiatives for action. The approach to change is constructed by three variables of change readiness: trigger identification, preparation for action and mode of action.
\end{abstract}

Keywords: Personal, Strategy. Change, Readiness, Plan, Objectives, Life style 


\section{Introduction}

Does it make sense to plan our future? Or should we just adjust our life based on continuous learning and developing circumstances? There is value in deliberate planning and there is value in being flexible. There is no right way, but it makes a lot of sense to combine the two approaches.

Deliberate strategy planning has the clear benefit that you don't leave the future to what just happens. You want to influence the future according to your priorities and desires. On the other hand, we know that we can't anticipate and control what happens to us in the future. A combination of deliberate strategy planning with the capacity for change readiness has the benefit of the two approaches.

Following is a story of a personal strategy:

In John's childhood he played football, baseball and basketball with his brothers in their backyard, but just for fun. He had no special athletic abilities.

When he was 15 years old he tried out for the school basketball team, but did not make it. At 5' 11 " he was too short to meet the minimum height standard for the game. 1t was unlikely that he would grow any taller as no one in his family was more than six feet tall.

When the school team went to its next tournament, they invited John along - but only as a personal assistant to carry the uniform of the star player!

From that day onwards, John decided that he would work on his basketball skills. He left home at 6am every day to practice before school began. He did this for a whole year.

With this effort, he finally made it to the school basketball team.

However, his team lost the first three tournaments after he joined.

But he had a routine and he never stopped practicing. He worked to improve every single move he made in basketball.

Finally, his efforts paid off, and as he left high school he won a college basketball scholarship.

What do you think happened to John after that?

This is the story of the deliberate and determined strategy of Michael Jordan!

(Source of story: Professor Rob Anthony, Hult International Business School and Wikipedia)

Covey (1989) first habit of highly effective people is: Be proactive.

Proactive people determine the agendas they will follow and choose their responses to what happens around them. The ability to influence what happens to us is based on guidelines, which can be viewed as our personal strategy. We can distinguish between long term, major strategies that happen at key turning points in our life and strategic thinking of a continuous nature. Examples of the first category are decision like getting married, buying a house, 


\section{Macrothink}

choosing an occupation and changing careers or living location. Examples of the second category include balancing decisions about the allocation of time between work and family, decisions about vacations, children education, on going investments, and mode of communications at work and home. From what we know, thinking strategically both in personal affairs as well as in business has a major impact on our probability of success.

Effective personal strategy means being able to think in multiple time frames, clarifying what one is trying to achieve over time as well as what needs to be done in the short term in order to get there. It also requires some order of organized thinking of the strategic issues one faces.

The following steps are useful in preparing a deliberate personal strategy. Carrying out this process provides clear guidelines for action and a better understanding of our priorities.

1. What is important to me in life? What is my vision, what kind of life style do I want?

2. What are my general objectives? What are the priorities?

3. What initiatives do I need to start? What do I need or want to learn?

4. How should I allocate my time and money?

5. What targets should I set? What feedback do I need? How do I assess or measure my progress?

We could map a deliberate personal strategy utilizing the strategy maps of the Balanced Score Card in business. (Kaplan and Norton 2000, Hollingworth, 2005). See Figure 1. The map is designed to be expanded horizontally to cover each objective with specific initiatives and learning projects. The Balanced Score Card approach helps in implementing a general strategy by expressing it in operational terms, as outlined in the five steps. The graphical presentation clarifies the steps and shows the cause and effect relationships: Learning and growth help carry out the initiatives, the initiatives make it possible to achieve the objectives, which contribute to life satisfaction. Further details are clarified in the following paragraphs. 


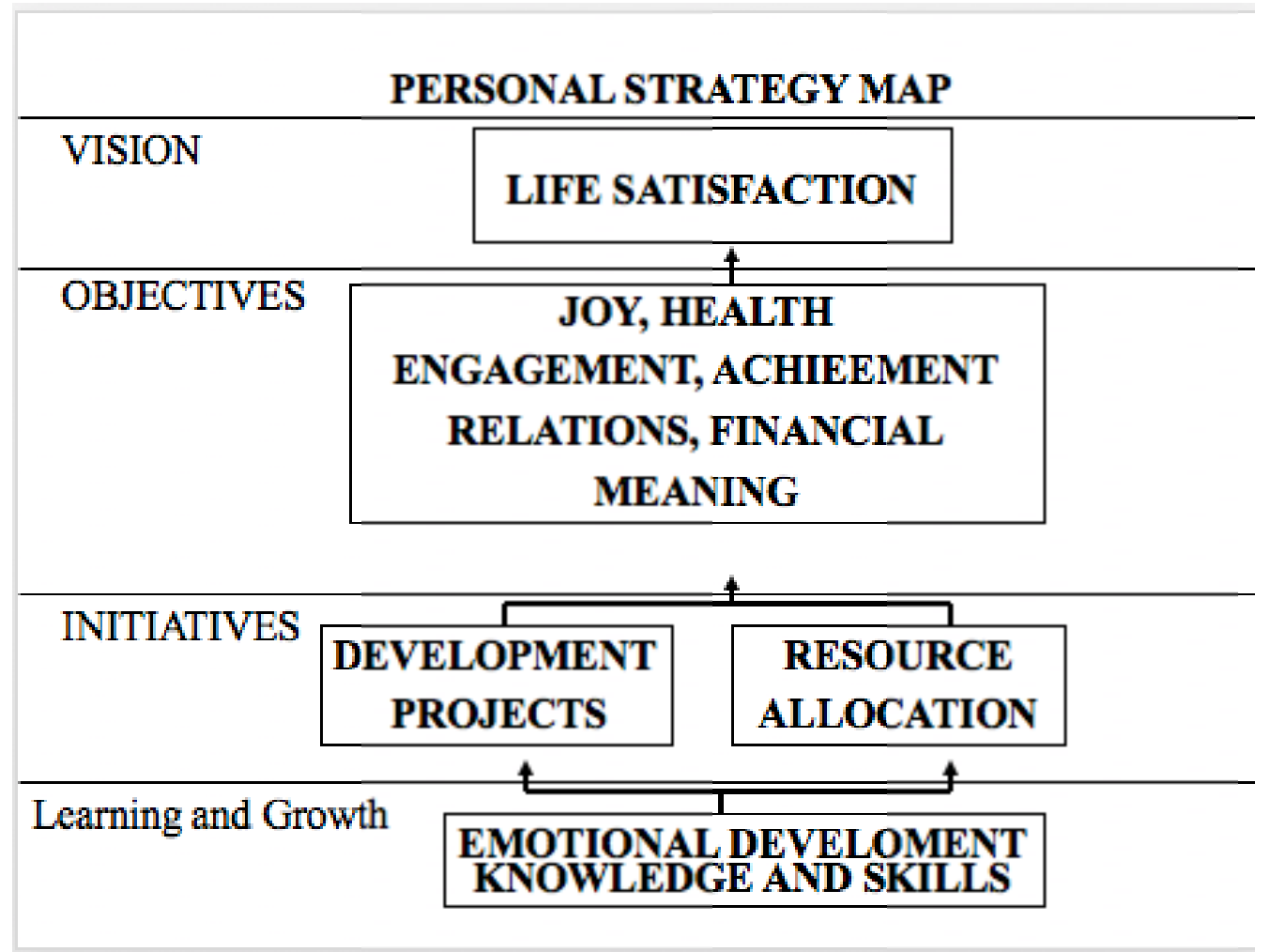

Figure 1.

\section{Vision, life styles and objectives}

In recent years psychologists have developed key components of well-being or flourishing in life (Zeligman , 2011):

1. Positive emotions (enjoying pleasant life and good health)

2. Engagement (involvement in a challenging and interesting activity)

3. Positive relationships (family, friends, community)

4. Achievement (accomplishment and financial wealth)

5. Meaning (Contribution to a valuable cause, spiritual activity)

There are five categories in this model of well-being. But in developing personal objectives it makes sense to separate positive emotions into two categories: 1 . Searching joy in life and 2. Maintaining and improving good health.

The category of achievement can also be separated into two categories: 1 . Professional and position accomplishment, 2. Achieving financial wealth.

We can view these seven components as life-satisfaction objectives. When people assign high priority to any one of these objectives we can classify them by life styles. 
Choice of a lifestyle is like choosing a vision as to how one's wants to live. What is the dominant driver that is and should determine strategy, decision-making and action? Here are some groupings of people according to general life styles:

Believers: these are usually people who have a strong religious belief and a desire for a spiritual life. They choose to follow the guidelines that are dictated by the religion of choice. The concept of a religion in this life style could apply to different ideologies beyond the traditional religions. Some of the radical believers are even willing to sacrifice their life for the religion ideology. These people combine a priority for "meaning" with a "positive relationship" within a community.

Belongers: For these people the most important driver in life is to be part of a tribe and to contribute to the well being of the chosen tribe. The biggest group in this category is family-oriented people who view every move in life in term of contribution to the well being of their family. When they go on vacation they are looking for a place that their kids will enjoy. "Positiverelationship" is the first priority for this group.

Achievers and Strivers: These people are "achievement" oriented, and they try hard to advance in their professional careers and achieve better financial wealth. When they go on vacation they want to combine business and pleasure.

Joy seekers: These people are placing a high priority on joyful situations in life contributing to "positive emotions". It could be achieved by collecting experiences, and also by giving preference to current good feeling in different forms including food, parties, travel etc. These people are likely to know the best restaurants in town.

Social commitment people: These people are willing to sacrifice many joyful and fulfilling things in life in order to make a contribution to a societal cause such as helping the poor, or environmental preservation. They are searching for "Meaning" and contribution in their daily life. Viktor Frankl (Frankl 1984) argued that our primary drive in life is not pleasure, as Freud maintained, but the discovery and pursuit of what we personally find meaningful.

Seekers of challenge and interest: These people put top priority in allocating their life and resources to a challenge, or to a subject, which interest and engage them. Typical subjects are science, music, sports and art.

Health consciousness people: These people place a very high priority on healthy living. They are likely to place high priority on eating organic food, regular exercise and living in a clean environment.

Most people follow some combination of these categories with different weights given to alternative life styles. Many people pass through their lives never questioning what they want. Some find it difficult to achieve a satisfactory balance between achievement at work and family relationship. Many others find it difficult to balance financial and engagement goals.

It is interesting to note that when the economy improves with more job opportunities, organizations are recognizing the need to dramatically improve employee engagement as they face a looming crisis in retaining good employees. (Deloitte survey, 2015). 
It is important to recognize that most of the objectives, like engagement, relationships, good health, enjoyment and meaning are oriented toward a continuous life process rather than achieving a specific end goal.

The majority of people don't allocate priorities in a very explicit way. Some will find it difficult, or unrealistic, to allocate 100 points to the various components of life satisfaction, or happiness. But most can probably reveal their preferences by making choices between alternative life scenarios based on various levels of the seven components. For example, what life scenario is preferable?

\begin{tabular}{|c|c|c|c|}
\hline & $\underline{\text { Scenario } 1}$ & $\underline{\text { Scenario } 2}$ & Scenario 3 \\
\hline Joy in life & High & Moderate & Moderate \\
\hline Good health & Moderate & High & Moderate \\
\hline High engagement & Moderate & High & Moderate \\
\hline Positive relationship & Moderate & High & Moderate \\
\hline Professional success & Moderate & Moderate & High \\
\hline Financial wealth & Moderate & Moderate & High \\
\hline Meaning/contribution & Low & High & Low \\
\hline
\end{tabular}

Clear priorities can be derived from these comparisons.(The statistical technique of conjoint analysis can generate a quantitative preference function based on revealed references). (Parry 2004)

Precise quantification of priorities is seldom done; it is helpful, but not essential. However, a clear understanding of the priorities in one's life is very important in order to generate guidelines for action.

\section{Translation of general objectives to operational terms - initiatives and learning.}

In order to achieve our general objectives, we need to take action of two kinds: initiatives and learning. If you want to initiate a change in your career you may need to learn new skills and then to start a search process for a new job. If you want to improve your health you may need to start an exercise program. In order to improve your relationships, or professional success, you may want to improve your emotional intelligence by hiring a coach or taking a relevant workshop. If you want to have more fun thru travel you may need to make specific plans. Some of the initiatives could be relevant for more than one objective. For example, a new job could contribute to professional achievement, financial wealth and high engagement. It is important to remember that you may have different opinions about certain moves after you try them. Experimentation is therefore part of effective initiatives. Going into new territory requires intelligence and learning.

It is useful to clarify the assumptions we make in deciding on specific initiatives or experiments. If our assumptions turned out, in time, to be wrong, we may need to change our 
plan.

Financial considerations require special attention. Positive cash flow is a critical factor for many activities in life. It is therefore important to monitor expected income and expenses, including timing, in order to make sure that all projects can be carried out as planned.

The specific strategy that will be developed at this stage is usually based on two types of analyses: an internal analysis and an external analysis.

The internal analysis includes assessments of personal strengths and weaknesses. It is useful to understand our weaknesses, but strategy should be built on strengths. What am I good at? What do I enjoy doing? Who do I like to be with? What did I learn from my past experiences? Strengths go beyond talent; it is also a reflection of knowledge and experience. A clear understanding of a person's unique capabilities and interests is a key to formulating a personal strategy. Nurturing and practicing your strengths is a major factor in life satisfaction, because you are more likely to be successful in what you are doing and enjoy doing it. (Clifton and Nelson 1995)

The external analysis includes assessments of opportunities and threats. If you want to change your career, you need to explore the demand and the potential compensation. If you are planning to retire you will need to explore whether your savings or pension are likely to be sufficient. If you think about changing your location, you need to explore the conditions of the area to which you want to move. While internal analysis requires us to review our past, in external analysis we look more to the future, living with uncertainty.

The internal and external analyses are the foundations for setting up specific initiatives in operational terms. We need to specify initiatives or projects in each one of our objectives. Some people are daring, or aggressive, in setting up bold and risky initiatives. Others are more careful and defensive. The strategic plan has to fit the personality and risk aversion of each individual. We could, of course, select a mix of some initiatives with high uncertainty and some initiatives with more limited uncertainty. Making commitments with a positive and optimal attitude tend to influence all concerned and as a result increase the probability of success.

It is valuable to recognize the difference between achieving short term and long term objectives. A typical tendency in business, as well as in personal life, is to concentrate too much on the short term and thus paying a significant price in achieving continuous and long term objectives. (Christensen 2010)

In order to make the initiatives operational we need to allocate resources to carry them out.

\section{Allocation of resources}

We have two main inputs to allocate to our projects or initiatives: Time and Money. For example, we may conclude that we need to allocate a few hours each day to improve our relationships with family and friends. On the other hand, we may conclude that in order to achieve our financial and professional goals we need to allocate more time to our projects at work. We may want to choose music as a career, but we realize we need to make enough 
money to feed our family and a musical career is not likely to satisfy our financial needs.

There are a number of ways to resolve the conflict:

First, we could follow our key priorities with the understanding that we have to make choices and not all objectives can be achieved. Most successful people in sports, music, science and arts have a history of devoting their life to one major priority with high engagement. You could think of the history of personalities like Albert Einstein, Steve Jobs, Steven Spielberg, Yehudi Menuhin and Michael Jordan. If a person has a clear knowledge what he loves to do, or he can find out his unique capability, high engagement in the area of choice is a key to life satisfaction and strategic success.

A second possible solution could be time-based, which means we could decide on one type of priority allocation for a period of time with the idea that this will change some time in the future. The change of priorities over time is a common observable strategy. For example, young ambitious people out of college could devote most of their time to success in college; later on, allocation might shift to close romantic relationship with a potential mate. Once married they may shift their focus to being successful at work and near retirement the focus will shift to good health and enjoyable travel.

A third possible resolution is to go back to our priorities and explore if we want to modify, or compromise, the original set in view of the conflicts over specific actions and time allocation. This is a typical process of people who are looking for balanced life. Working parents is the norm for most families in America and the trade-off between work obligations, children care, household duties and recreation is difficult. Working parents say they feel stressed, tired, rushed and short on quality time with their children, friends, partners or hobbies, according to a new Pew Research Center survey. (NYTimes, Nov. 4, 2015). A clear understanding of the cost of compromise does not solve the conflict, but could make it easier to accept.

It is highly desirable that each of the seven objectives receive some priority with attention to initiatives and resource allocation. Otherwise, a person may feel that key elements for his life satisfaction are missing, even if he is very successful in other areas. For example, a person with high accomplishments in a specific field could feel regret and pain for ignoring his family completely.

It is important to add that we don't need to view the resources as a fixed sum. We can borrow money and we can engage other people to help us carry out the workload and the initiatives we set.

The life story of Michael Jordan demonstrates the impact of hard work in addition to talent. Most high achievers don't stop at being "good enough", but strive to be great by doing an incredible amount of work.

\section{Targets and feedback}

There is a big difference between a general goal to spend more time with our children and a specific plan to spend 10 hours a week with them. We are much more likely to achieve our goals if we set specific and measurable targets. We tend to follow tasks that can be measured 
rather than tasks that are stated in general non-specific terms. Targets and measures make it possible for us get feedback on how well we are performing our plan. Since reality is likely to be different than our expectation, the feedback is critical for making timely changes to our strategy and plans.

\section{Change readiness}

Most strategies in life, in business and in war, are not carried out as planned.

Change is frequently needed, but many people find it difficult to get out of their familiar comfort zone. The uncertainty associated with change is sometimes a deterrent to the recognition of the need and to timely action. There is a large body of literature, which deals with the psychology of getting people to accept changes in life.

We can distinguish five main reasons for a change in personal strategy:

1. Need for a turnaround - the strategy we chose did not work as predicted.

2. Desire for change - the strategy we chose does not satisfy us any more. For example, we want more adventure, variety and fun in life.

3. We carried out some experiments, which point to a new direction in our life.

4. Our strategy was based on certain assumptions which turned out to be wrong.

5. Change in circumstances - environmental impact.

The first four reasons should lead to rethinking of our strategic plan. We need to review our priorities and examine the relationship between inputs and output for each objective. A revised plan is called for.

Change of circumstances is continuous. Every day we need to change something. For some people, change is an opportunity. The daily changes are usually relatively mild; to some extent predictable with a limited influence on our strategic decisions.

But the biggest impact on our life is changes that are not predictable. These potential changes cause great uncertainty, which can disrupt our best plans. Typical developments that require a change of strategy include:

1. Job disappearance or drastically changed. Technological development and globalization make this more common.

2. Relationship deterioration.

3. Health deterioration. This is more predictable at older age.

4. Financial deterioration like a sharp decline in the stock market or a major change in interest rates.

5. Military or political upheaval. A recent consequence is the immigration of people from Syria to Europe. 


\section{Macrothink}

Journal of Management Research

ISSN 1941-899X

2016, Vol. 8, No. 1

It is important to explore how can we be ready to take proper action in response to unpredictable change?

We can view change readiness as a construct consisting of three related activities: 1. Trigger identification 2. Preparation for action and 3. Action novelty. These elements identify personal ability to cope with opportunities and threats. (Timmor and Zif, 2010) See Figure 2.

\section{A SCHEMATIC MODEL OF CHANGE READINESS}

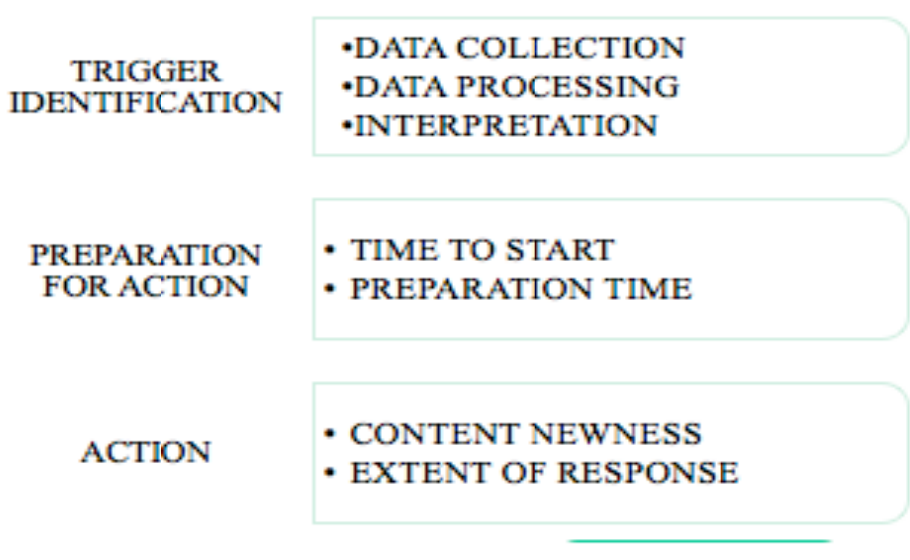

Figure 2.

Opportunities and threats are frequently external events; however, they are highly distinct from one another. The former is a highly favorable situation, and is an indication of a chance to substantially improve performance. The latter, on the other hand, is a highly unfavorable situation, and indication of pending deterioration in well-being if some action is not taken. While it is true that in many cases a threat can be viewed as an opportunity and vice versa, most people tend to identify environmental signals either as threats or as opportunities, and the strategic literature frequently classifies outside events into threats or opportunities (Ansoff 1984).

The first step in a person's readiness to cope with new conditions is trigger identification. First is the need to properly monitor relevant developments and intercept signals for trigger sources. At the early stages of a major change some of the signals could be quite weak. There is a need to invest time and money in monitoring not only the external environment but also personal developments in health and relationships. Second, the observed signals should be processed to separate meaningful developments from random noise and expected likelihood of occurrence, impact, and timing. The third step requires translation of the findings into a conclusion that some response is necessary or desirable. Typical mistakes that people make at this stage is denying a threat signal, or concluding that there is no problem or no need for 


\section{Macrothink Institute ${ }^{\mathrm{TM}}$}

action. A few Examples of these mistakes: a laboratory test of positive finding, which requires treatment, a business assumption about a potential market, which is not materializing and a deteriorating job situation. Being aware of the personal tendency to reject signals with threatening consequences could possibly help in making a more objective assessment.

The second phase of change readiness is preparation for action. Recognizing a need, or an opportunity, is a necessary but insufficient condition for undertaking strategic change. The second variable therefore deals with the time it takes to respond. The time response variable, however, is not detached from the environment-monitoring variable: If the person is slow in identifying an environmental threat, then the time available for preparing action might be quite short (Ansoff 1984).

See Figure 3 for four combinations (A, B, C, and D) of trigger identification and rate of response: A reflects early signal identification and quick response, $\mathrm{B}$ reflects early signal identification and slow response, $\mathrm{C}$ reflects slow signal identification and quick response and $\mathrm{D}$ reflects slow signal identification and slow response. In similarity with a medical condition, an early identification of a need for change increases the likelihood of success with the action taken.

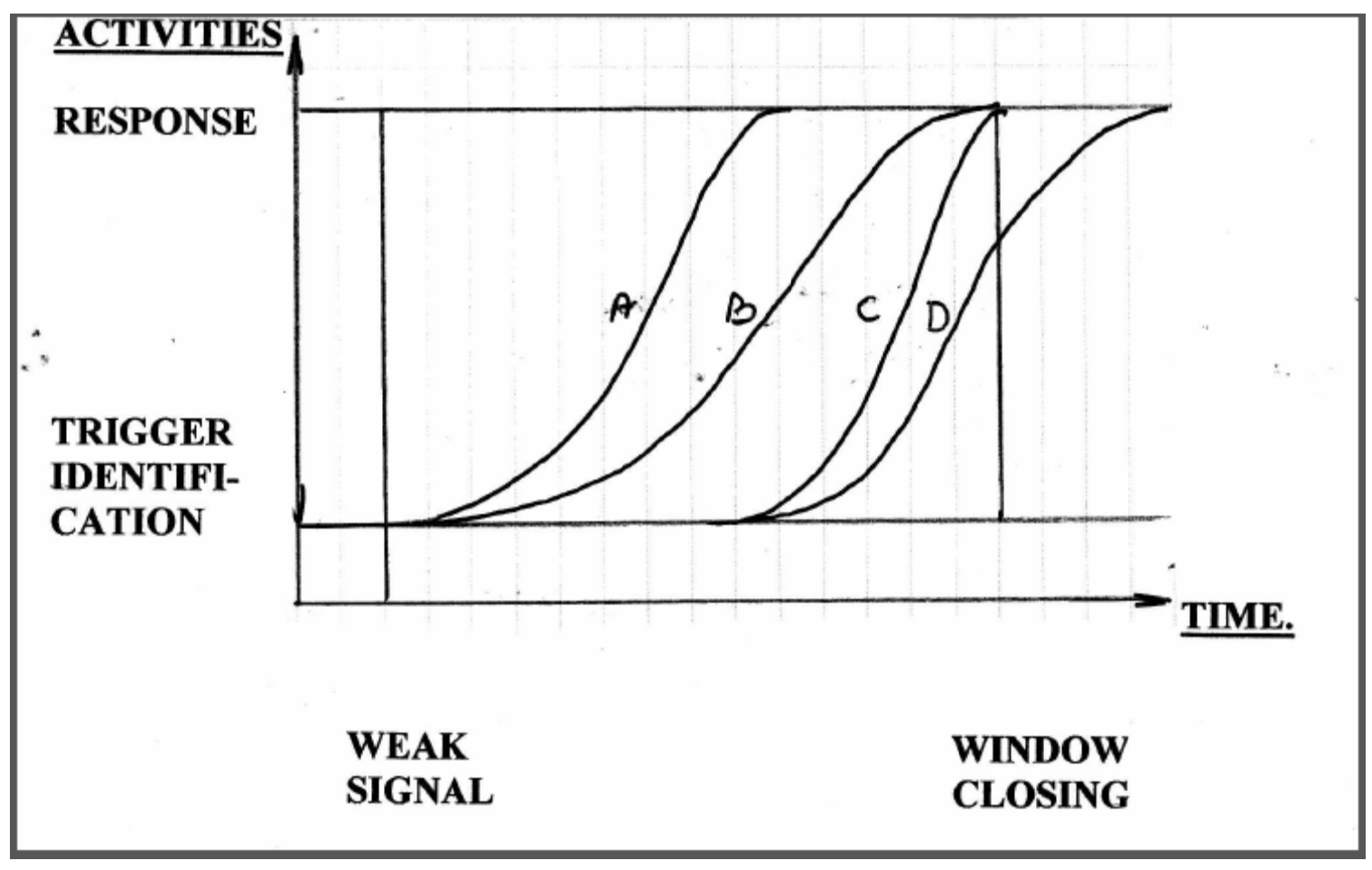

Figure 3. Signal Recognition and Rate of Response

Jack Walsh quotation: Change before you have to! Is relevant in this connection. Response time can be assessed by two parameters: 1 . Time to start; and 2. Preparation time. The first refers to the lag between the recognition of the need to change and the start of active preparation. This lag reflects the person's readiness for taking changing action. People who tend to postpone making key decisions are likely to have a long lag prior to the start of action 
preparation. Others could be overly occupied with current projects or crises, or finding it difficult to put aside existing activities.

Preparation time is content-related, i.e., if a new development requires a change of occupation with learning new knowledge and skills then a long preparation time is inevitable.

It has been argued that the speed, with which one moves to translate trigger identification for action, is the most critical component for successful strategic change. (Kotter, 2008)

The third dimension of change readiness is the action of response, or more specifically, the degree to which the personal response to the environmental triggers is appropriate, or innovative. Sometimes a minor change or no action is sufficient. For example, you can decide not to sell your stock after the market declined sharply. In other cases, an incremental action, like doing more of the same, is the wrong response. In turbulent environments, effective strategic change is highly associated with renewal of competencies and action innovations rather than an attempt to defend existing strategies. Confusing the need for transformational change with incremental moves is a typical mistake. Reactive activity, which reflects tactical flexibility, may be less effective for the long haul when major changes are taking place.

A personal capability of executing a novel and energetic response, when such response is called for, could lead to success in overcoming negative developments and taking advantage of positive opportunities.

\section{Conclusion}

The paper emphasizes the notion that effective personal strategy has to balance a specific plan with the need for change. We need to distinguish between minor changes that occur continuously and major environmental shifts that require rethinking of our key assumptions. As we set a deliberate and stable strategy we need to keep learning of new opportunities and threats. This is not easy, since most of us have a strong inertia to continue with our life plan and to resist change as long as possible.

When we think of strategy we think of the future and what we need to start doing today to have a desired future. But good strategy takes into account what we learnt about our strengths and capabilities in the past. We need to remember that it is our abilities and not our disabilities, which count.

A positive attitude, a daring plan and some persistence in execution can lead to better outcomes than most people expect. A daring plan can lead to some failures. Many successful people faced early failures in their chosen career. But failures should be viewed as experiments to learn from rather than a permanent disappointment and retreat.

The barriers to successful implementation of a personal strategy are: Choosing objectives and initiatives which are not actionable, a strategy that is too rigid or too loose, poor allocation of resources to our initiatives, missing signals of relevant environmental changes and slow or weak response to such changes. 


\section{Macrothink}

\section{References}

Ansoff, H. I., \& Mcdonnell E. J. (1984). Implanting Strategic Management, (2 ${ }^{\text {nd }}$ ed,) New York, NY: Prentice Hall.

Christensen C. M. (2010). How Will You Measure Your Life?, Harvard Business Review, July-August.

Clifton D. O., \& Nelson P. (1995). Soar with your Strengths: A Simple yet Revolutionary Philosophy of Business and Management, New York: Dell.

Covey S. R. (1989). The Seven Habits of Highly Effective People, New York, N.Y.: The Free Press.

Frankl V. E. (1984 \& 1992). Men's Search for Meaning, New York, N. Y.: Washington Square Press.

Deloitte Survey, Global Human Capital Trends. (2015). ww2.deloitte.com/us/en/pages/human-capital/articles/introduction-human-capital-trends.html Hollingworth M. (2005). Resolving the Dilemma of Work Life Balance: Developing Life Maps, Ivy Business Journal, Nov.-Dec. (http://iveybusinessjournal.com/ibj_issue/november-december-2005)

Kaplan R. S., \& Norton D. P. (2007). Using the Balanced Score Card as a Strategic Management System. Harvard Business Review, July-August.

Kaplan R. S., \& Norton D. P. (2000). Having trouble with your strategy then map it. Harvard Business Review, Sept.-Oct.

Kotter J. P. (2008). A Sense of Urgency, Boston Ma. :Harvard Business Press.

Mintzberg H. (1987). Crafting Strategy. Harvard Business Review, July-August.

Parry M. (2004). Conjoint Analysis, Charlottesville VA. :Darden Business Publishing

Yaron Timmor and Jehiel Zif. (2010). Change Readiness: An Alternative Conceptual and Empirical Examination. EuroMed Journal of Business.

Zeligman M. E. (2011). Flourish: A Visionary New Understanding of Happiness and Well-Being, New York, N.Y.: Free Press 